\title{
Pengaruh Burnout Terhadap Kinerja Karyawan Hotel Crowne Plaza Bandung
}

\author{
Febrisa Yosanti ${ }^{1}$, Kasmita ${ }^{2}$ \\ ${ }^{1}$ Universitas Negeri Padang \\ ${ }^{2}$ Universitas Negeri Padang \\ email : febrisa04@gmail.com
}

\begin{abstract}
Abstrak: Penelitian ini bermaksud untuk menentukan adanya pengaruh burnout terhadap kinerja karyawan di hotel Crowne Plaza Bandung dengan jenis penelitian deskriptif kuantitatif menggunakan metode asosiatif kausal, dengan 112 orang sampel, memakai teknik sampel proportionate stratified random sampling. Data dikumpulkan dari hasil pengisian kuesioner memakai metode skala likert. Sedangkan data di analisis dengan uji regresi linear sederhana. Berdasarkan dari hasil pengujian hipotesis, diperoleh pengaruh yang positif dan signifikan antara burnout terhadap kinerja karyawan, dengan kontribusi pengaruh sebesar yaitu 7,3\% kemudian 92,7\% ditentukan oleh faktor lain.
\end{abstract}

Kata kunci : Burnout, Kinerja Karyawan

\section{PENDAHULUAN}

Menurut Undang-Undang Republik Indonesia No 10 Tahun 2009 "Pariwisata adalah keseluruhan kegiatan yang terkait dengan pariwisata dan bersifat multidimensi serta multidisiplin yang muncul sebagai wujud kebutuhan setiap orang dan negara serta interaksi antara konsumen, pemerintah daerah, dan pengusaha". Kegiatan pariwisata haruslah di dukung oleh ketersediaan akomodasi seperti hotel, wisma maupun jenis akomodasi lainnya [1].

Bandung merupakan salah satu destinasi wisata favorit di Indonesia, yang memiliki banyak hotel sebagai sarana penunjang sebuah destinasi wisata Salah satu hotel yang ada di kota Bandung yaitu Hotel Crowne Plaza, yang beralamat di Jl. Lembong No.19, Braga, Kec. Sumur Bandung, Kota Bandung, Jawa Barat. Hotel Crowna Plaza ini tergolong hotel bintang lima.

Karyawan hotel bintang 5 sering mengalami stress karena pekerjaan yang banyak terutama pada departemen Fo, Hk,FBS,Fbp, dan Engginering. Tingkat hunian kamar tinggi akan menjadi beban oleh karyawan yang dapat menurunkan kinerja karyawan [2]. Smentara itu karyawan tetap dituntut untuk fokus dan maksimal, mengurangi kesalahan dalam bekerja, menjaga atau merawat peralatan hotel, tidak membuat perihal yang mengakibatkan keluhan dari tamu. Uraian sebelumnya merupakan penyebab stress. Jika tingkat stress tinggi akan menimbulkan keinginan untuk keluar dari pekerjaan [2], juga dapat menyebabkan terjadinya burnout. "Burnout yaitu keadaan stress secara psikologis yang sangat ekstrem sehingga individu mengalami kelelahan emosional dan motivasi yang rendah untuk bekerja. Burnout dapat merupakan akibat dari stress kerja yang kronis" [4].

Sumber daya manusia (SDM) berperan sebagai penggerak kehidupan usaha. Sumber daya manusia berkualitas cenderung memliki kinerja yang lebih baik, upaya peningkatan kualitas sumber daya manusia sangat penting untuk diperhatikan oleh pimpinan. Tugas dari manajemen sumber daya manusia adalah untuk memanfaatkan dan mengoptimalkan kinerja karyawan. Karyawan memiliki kinerja yang 
optimal akan menjadi sasaran bagi suatu perusahaan karena kinerja merupakan kunci penting bagi perusahaan. serta karyawan yang dapat memperoleh hasil kerja maksimal [3].

Kinerja adalah hasil kerja secara kualitas dan kuantitas yang dicapai oleh seseorang pegawai dalam melaksanakan tugasnya sesuai dengan tangung jawab yang diberikan kepadanya [5]. Faktor-faktor mempengaruhi kinerja seperti efektiv dan efisien, otoritas dan tanggung jawab, disiplin, dan inisiatif [6]. Indikator kinerja sebagai berikut: kualitas, kuantitas, penggunaan waktu, dan Kerjasama [7].

\section{METODOLOGI}

Penelitian yang dilakukan tergolong pada kuantitatif, yang dijadikan populasi karyawan tetap, dengan teknik pengumpulan sampelnya adalah proportionate random sampling berjumlah 112 orang karyawan. Jenis data dalam penelitian ini adalah data primer dan data sekunder.Data primer diperoleh dengan menyebarkan angket sesuai skala likert dengan 5 skala, yang sebelumnya telah di uji cobakan terlebih dahulu dengan uji validitas dan uji reliabilitas, serta data sekunder untuk variabel kinerja karyawan di dapat dari HRD. Analisis data kedua variabel dilakukan dengan regresi linear sederhana, serta menentukan besar kecilnya pengaruh antar variable.

\section{HASIL DAN PEMBAHASAN}

\section{A. Hasil Penelitian}

\section{Deskripsi Data Variabel Burnout}

Data penelitian didapatkan dari jawaban pertanyaan sebanyak 15 butir yang di isi oleh seluruh responden.

Tabel 1. Distribusi Frekuensi Data Variabel Burnout

\begin{tabular}{|c|c|c|c|}
\hline Kategori & Rentang Skor & Frekuensi & Persentase \% \\
\hline Sangat Baik & $\geq 67,5$ & 14 & $12,5 \%$ \\
\hline Baik & $52,5-<67,5$ & 38 & $33,93 \%$ \\
\hline Cukup & $\mathbf{3 7 , 5}-<\mathbf{5 2 , 5}$ & $\mathbf{5 0}$ & $\mathbf{4 4 , 6 4 \%}$ \\
\hline Buruk & $22,5-<37,5$ & 9 & $8,04 \%$ \\
\hline Sangat Buruk & $<22,5$ & 1 & $0,89 \%$ \\
\hline \multicolumn{2}{|r|}{ Jumlah } & 112 & 100 \\
\hline
\end{tabular}

Hasil burnout 112 orang responden dijelaskan bahwa: 12,5\% kategori sangat baik, $33,93 \%$ baik, $44,64 \%$ cukup, $8,04 \%$ buruk, dan $0,89 \%$ sangat buruk.

\section{Deskripsi Data Variabel Kinerja Karyawan} responden.

Data penelitian didapatkan dari jawaban pertanyaan sebanyak 9 butir yang di isi oleh seluruh

Tabel 2. Distribusi Frekuensi Data Variabel Kinerja Karyawan $\mathrm{N}=112$

\begin{tabular}{|c|c|c|c|}
\hline Kategori & Rentang Skor & Frekuensi & Persentase \% \\
\hline Sangat Baik & $\geq 36$ & 47 & $41,97 \%$ \\
\hline Baik & $\mathbf{3 0}-<\mathbf{3 6}$ & $\mathbf{6 4}$ & $\mathbf{5 7 , 1 4 \%}$ \\
\hline Cukup & $24-<30$ & 1 & $0,89 \%$ \\
\hline Buruk & $18-<24$ & 0 & $0 \%$ \\
\hline Sangat Buruk & $<18$ & 0 & $0 \%$ \\
\hline \multicolumn{2}{|r|}{ Jumlah } & 112 & 100 \\
\hline
\end{tabular}

Hasil kinerja 112 orang karyawan, dapat dikelompokkan sebagai berikut: 41,97\% kategori sangat baik, 57,14\% kategori baik, 0,89\% cukup, serta tidak ada buruk dan sangat buruk. 


\section{Uji Persyaratan Analisis}

Berdasarkan uji persyaratan analisis, dapat disimpulkan bahwa kedua variabel berdistribusi normal, selanjutnya data bersifat homogen, seta terdapat hubungan yang linear.

\section{Pengujian Hipotesis}

Berdasarkan pengujian hipotesis, didapat koefisien regresi 0,058 dengan signifikansi 0,004 $<0,05$. Maka peningkatan 1 satuan variabel burnout meningkat menjadi 0,058 satuan kinerja karyawan. Jadi hipotesisnya adalah $\mathrm{H}_{\mathrm{a}}$ diterima $\mathrm{H}_{0}$ ditolak. Kemudian kontribusi pengaruh burnout terhadap kinerja karyawan 7,3\% kemudian 92,7\% ditentukan oleh faktor lainnya.

\section{B. Pembahasan}

\section{Burnout}

Berdasarkan penelitian yang telah dilakukan tentang variabel burnout, dapat dijelaskan dari 112 orang responden disimpulkan bahwa burnout digolongkan pada kategori cukup dengan presentase sebesar 44,64\%. Selanjutnya hasil deskripsi data perindikator dapat diklompokkan sebagai berikut: 1) kelelahan fisik, dikategorikan cukup, persentase $36.61 \%$, 2) kelelahan emosional, dikategorikan cukup, persentaase 41,07\%,3) kelelahan mental, persentase 56,25\% dikategorikan sangat baik. Menurut King (2010) Burnout yaitu keadaan stress secara psikologis yang sangat ekstrem sehingga individu mengalami kelelahan emosional dan motivasi yang rendah untuk bekerja. Burnout dapat merupakan akibat dari stress kerja yang kronis.

Pengaruh Burnout dapat di kategorikan cukup, seharusnya pihak hotel harus mengkaji kembali mengenai burnout yang terjadi pada karyawan hotel crowne plaza Bandung.

\section{Kinerja Karyawan}

Setelah dilakukan penelitian di hotel crowne plaza Bandung, dapat dijelaskan dari 112 responden bahwa kinerja karyawan digolongkan pada kategorikan baik dengan $57,14 \%$. Kinerja merupakan hasil pekerjaan yang mempunyai hubungan kuat dengan tujuan strategis organisasi, kepuasan konsumen, dan memberikan kontribusi pada ekonomi [10]. Berdasarkan uraian di atas, dapat disimpulkan kinerja karyawan baik, seharusnya karyawan Hotel Crowne Plaza harus mempertahankan serta meningkatkan kinerja karyawannya, karena kinerja yang bagus dapat mendapatkan citra yang baik, dan begitu juga sebaliknya.

\section{Pengaruh Burnout Terhadap Kinerja}

Kontribusi Pengaruh burnout terhadap kinerja sebesar 7,3\%. Kemudian 92,7\% dengan tingkat signifikan 0,004 $<0,05$ berarti burnout berpengaruh secara signifikan terhadap kinerja karyawan. Dengan demikian burnout yang dialami karyawan mempengaruhi kinerja karyawan tersebut, peningkatan burn out akan mengurangi kinerja karyawan. Karyawan yang mengalami kelelahan secara fisik dan emosional akan berdampak tidak baik bagi kinerja organisasi secara keseluruhan.[3].Bahkan jika dibiarkan dapat menyebabkan keinginan dari karyawan untuk meninggalkan organisasi [2].

\section{KESIMPULAN}

1. Secara keseluruhan burnout di Hotel Crowne Plaza Bandung menunjukkan kategori cukup dengan persentase $44,62 \%$. Sedangkan berdasarkan 3 indikator, terdapat 1 indikator kategori sangat baik yaitu indikator kelelahan mental serta 2 indikator dengan kategori cukup, yaitu indikator kelelahan fisik dan kelelahan emosional.

2. Kinerja karyawandi Hotel Crowne Plaza Bandung, secara keseluruhan karyawan tergolong baik dengan persentase 57,14\%. Selanjutnya berdasarkan 2 indikator, terdapat 1 indikator dengan kategori sangat baik yaitu indikator kuantitas kerja serta 1 indikator kategori baik yaitu indikator kualitas kerja.

3. Berdasarkan dari hasil penelitian diperoleh pengaruh variabel burnout terhadap kinerja karyawan sebesar 7,3\% sedangkan $92,7 \%$ ditentukan oleh factor lain. Jadi hipotesisnya adalah $\mathrm{H}_{\mathrm{a}}$ diterima $\mathrm{H}_{0}$ ditolak. 


\section{DAFTAR PUSTAKA}

[1] Pasaribu, T. Putra, and Y. P. Lisna, "WHAT SERVICESCAPES SHOULD BE PRIORITIZED IN THE HOSPITALITY CENTER, UNIVERSITAS NEGERI PADANG," J. Bus. Hosp. Tour., vol. 4, no. 2, pp. 73-80, 2018, doi: 10.1051/matecconf/201712107005.

[2] I. Meirina, F. Ferdian, P. Pasaribu, and H. Suyuthie, "the Influence of Work Environment Towards Turnover Intention of Employee of 4 Star Hotels in Padang City," J. Bus. Hosp. Tour., vol. 4, no. 2, pp. 1-8, 2018, doi: 10.22334/jbhost.v4i2.120.

[3] Susiani; and H. Suyuthie, "PENGARUH BUDAYA ORGANISASI TERHADAP KINERJA KARYAWAN DI THE AXANA HOTEL PADANG," Mimb. J. Penelit. Sos. dan Polit., vol. 8, no. 2, pp. 98-104, 2019, [Online]. Available: https://journals.unihaz.ac.id/index.php/mimbar/issue/view/126.

[4] King, Laura. 2010. Psikologi Umum. Jakarta : Salemba Humanika.

[5] Edy, Sutrisno,(2016). Manajemen Sumber Daya Manusia. Jakarta : Kencana Prenada Media Group

[6] Fendy Levy Kambey, Suharnomo,(2013). Pengaruh Pembinaan, Pelatihan, Pengembangan, Pemberdayaan,dan Partisipasi Terhadap Kinerja Karyawan(Studi Pada Pt. Njonja Meneer Semarang), Jurnal Studi Manajemen dan OrganisasiVol. 10, No. 2, Juli, Thn. 2013, Halaman 142-151

[7] Yuliandani dan Fetty. 2015,Judul "Pengaruh Pelatihan Pelayanan Terhadap Kinerja Karyawan Anggrek Shopping Hotel Bandung"

[8] Human Resource Departmen Hotel Crowne Plaza Bandung

[9] Undang - Undang No 10 tentang Pariwisata

[10] Wibowo. 2013. Manajemen Kinerja. Jakarta: Rajawalio Pers. 